\title{
Comparative assessment of safety and efficacy of inhaled corticosteroids: Report of a Committee of the Canadian Thoracic Society
}

\author{
L-P. Boulet*, D.W. Cockcroft**, J. Toogood + ,Y. Lacasse*, J. Baskerville+, F.E. Hargreave ${ }^{\S}$
}

\section{CONTENTS}

Introduction (L-P. Boulet, F.E. Hargreave). General considerations (L-P. Boulet, F.E. Hargreave, D.W. Cockcroft, J. Toogood).............. 1194 Assessing bioequivalence or relative potency.........1196 Clinical trials (L-P. Boulet, Y. Lacasse).
1194

1196

Bronchoprovocation tests (D.W. Cockcroft). 1199 Steroid reduction model (F.E. Hargreave).

Recommendations with regard to efficacy 1201 Assessing systemic bioequivalence and relative safety (J. Toogood, J. Baskerville).
Asthma is an inflammatory disease characterized by reversible airflow limitation and hyperresponsiveness [1]. Inhaled corticosteroids (ICS) are considered the mainstay of asthma treatment $[2,3]$. Their role in the treatment of asthma has been reviewed recently [4-6]. Since the introduction of beclomethasone more than 25 yrs ago, new topical corticosteroids such as triamcinolone, flunisolide, budesonide and fluticasone have been introduced. Also, the patent on beclomethasone has expired in many countries, making the introduction of generic preparations possible. New modes of delivery of drugs have been developed, including different types of powder devices and spacers. New propellants, such as hydrofluoroalkanes (HFA), should shortly replace chlorofluorocarbons (CFC), eliminated for environmental reasons [7]. Clinical efficacy may be assumed from pharmacological equivalence, but for therapeutic equivalence and systemic effects, it should, ideally, be demonstrated $[8,9]$.

Government agencies, industry and clinicians are, therefore, faced with the task of evaluating the comparative safety and efficacy of generic preparations, and different corticosteroids, delivery systems and aerosol formulations. As a result, the Canadian Thoracic Society, with the support of Health Canada, asked its Asthma Committee to perform this task. Two symposia were held, the first in Seattle in May 1995 (which included international experts) and the other in Toronto in December 1995. Another objective of the Committee was to suggest a model that could be tested through a National Study and, if data were insufficient to do this, determine what other studies should be conducted. This document summarizes these discussions and adds data from recent publications.

\section{General considerations}

The therapeutic effect of inhaled agents is influenced by a number of factors, such as the therapeutic potency of the agent and the amount reaching the airways of the lungs, the latter depending on the type of inhaler used, aerosol properties and the inhalation technique [10-12].

In comparing different drugs, knowledge of the clinical bioequivalence is useful. Recommendations to determine bioequivalence of agents such as ICS have been published by the British Association for Lung Research [13]. Pharmacodynamic evaluation is considered important when comparing inhaled medications. With regard to clinical trials, long-term (>1 month) studies in subjects of a range of ages and disease severity are recommended. Safety assessments should include integrity of the hypothalamopituitary-adrenal (HPA) axis and incidence of local side-effects, while efficacy is determined by parameters such as morning and evening peak expiratory flows (PEF), bronchoprovocation studies and number of asthma exacerbations.

Systemic bioavailability will depend mainly on the absorption of the drug through the bronchopulmonary vascular bed and to a lesser degree, on gastrointestinal absorption [10, 14, 15]. The best agent would have good topical corticosteroid action from pulmonary tract deposition, little absorption through the gastrointestinal tract and be inactivated or eliminated rapidly from the circulation.

\section{Safety/efficacy ratio}

In comparing ICS, an assessment should be made, not only of the efficacy in terms of dosing, but also of the

*Centre de Pneumologie de l'Hôpital Laval, Université Laval, Sainte-Foy, Québec, Canada. **Dept of Medicine, Division of Medicine, Royal University Hospital, Saskatoon, Saskatchewan, Canada. +University of Western Ontario and London Health Sciences Centre, London, Ontario, Canada. $\S$ Asthma Research Group, St Joseph's Hospital, and Mc Master University, Hamilton, Ontario, Canada.

Correspondence: L-P. Boulet, Hôpital Laval, 2725, Chemin Sainte-Foy, Sainte-Foy, Québec, Canada G1V 4G5, Fax: 1418 6564762

Received: June 23 1997; Accepted after revision August 261997

Supported by Health Canada. 
relationship of the different doses between the therapeutic and adverse effects (particularly if these are systemic).

\section{Factors to be considered in comparative studies}

When comparing the efficacy and safety of new ICS to agents previously approved for asthma treatment, many factors should be considered (table 1). Some of these relate to the nature of the drug and its mode of administration (including the type of device and aerosol formulation), the type and severity of asthma (including the degree of airway inflammation) and concomitant treatment. Other factors relate to the study design, the choice of control population and the outcomes.

\section{Inhalation technique}

Among the conditions that may influence the intrapulmonary delivery of drugs inhaled via a pressurized metered-dose inhaler (pMDI), the following are known to be important:

1) With the closed mouth technique, reflex gagging and cough may reduce intrapulmonary drug priming delivery in some subjects. The open mouth technique minimizes this problem.

2) Failure to shake the pMDI between each puff can materially reduce the amount of drug expelled from the pressurized canister [16].

3) Variations in the timelapse between expelling the drug and the start of inspiration [17-20].

4) Variations in the point in the respiratory cycle at which drug inspiration commences, e.g. residual volume or functional residual capacity (FRC) [21, 22].

5) The rate at which the drug is inspired [20, 23].

6 ) The presence and duration of a post-inspiratory breathhold [21]. More specifically, intrapulmonary drug delivery

Table 1. - Factors influencing comparative efficacy and safety of inhaled corticosteroids

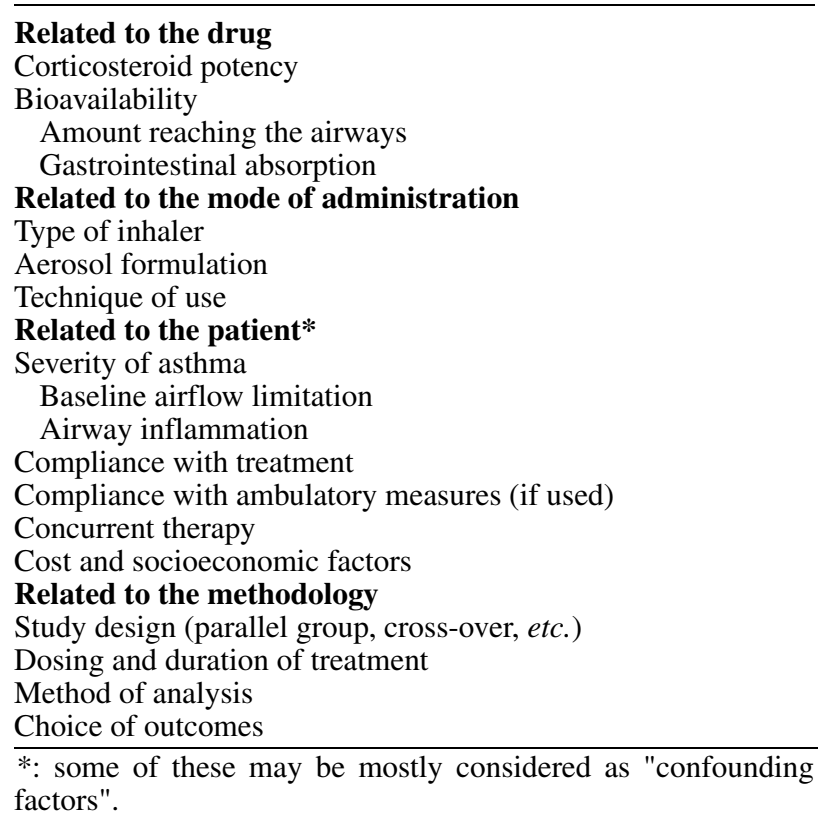

will be reduced if there is inadequate coordination between inspiration and delivery of the drug, if the delivery occurs too late during inspiration, if inspiratory flow is too rapid and if post-inspiratory breath-hold is too short.

Inspiration should start at FRC immediately before expelling the dose from the pMDI, proceed at 25-30 L.min ${ }^{-1}$ to total lung capacity, and be followed by a $5-10 \mathrm{~s}$ breath hold before exhalation [21]. The technical support staff and test subjects require training to ensure uniformity of the methods of drug administration at each investigative site. Preliminary uniformity trials may be indicated to confirm the efficacy of this training. Repetition of such trials is desirable whenever a major change in personnel or equipment occurs at any of the investigative centres.

In regard to powder inhalers, factors such as inspiratory flow may markedly influence the dose inhaled as it should be sufficient to ensure the penetration of the powder into the lower airways. Powder device efficacy may be affected by humidity.

\section{The issue of compliance}

In many previous studies comparing ICS, compliance was not monitored. Compliance with regular therapy is known to be low, overall being estimated to be about $50 \%$ of the prescribed dose; therefore, it is preferable to have some measure of compliance such as canister weight, pill counts, daily record and interview [22-24]. Some electronic devices have been used to count the number of inhalations in some research projects [23]. Compliance with the monitoring of PEF used in many trials also needs to be considered; it is poor when the study is longer than 3 months or if patients are not motivated to do these measurements [25]. Compliance may be used as a covariate in the data analysis.

\section{Statistical analysis and clinical significance of the results}

Establishment of confidence intervals has been suggested as an adequate approach to equivalence testing of drug formulations [26]. It defines the maximum acceptable difference between formulations that can still be considered clinically equivalent. The confidence intervals of the differences should fall within predetermined limits.

A method that allows the detection of small differences in efficacy between two or more inhaled drugs is considered ideal for the assessment of new agents. Consideration should be given to whether the observed difference is clinically relevant, particularly when there is a considerable difference in cost or ease of administration.

Finally, in order to validate a comparative potency model, it is necessary to demonstrate that the model can differentiate between different doses of the same inhaled corticosteroid. It should be able to demonstrate a doseresponse effect.

\section{Conclusion}

There is no validated method available to compare ICS potency. A simple validated method for evaluating relative potency of ICS is needed. Many factors should be considered when comparing efficacy and safety of ICS. Some of these have been discussed above and others will be mentioned below. 
Assessing bioequivalence or relative potency

\section{Clinical trials}

A large number of clinical trials comparing the efficacy and safety of different ICS have been conducted over the last 20 yrs [5, 27]. Some have attempted, with limited success, to identify the relative potency of different ICS and to determine the therapeutic equivalence of currently used ICS and newly developed agents $[10,13]$. There is, however, a need for standardized models and specific evaluation criteria. A number of important methodological aspects and potential pitfalls should be considered if a valid comparative study of ICS is to be undertaken. These include: 1) a clear identification of the drugs under study; 2) an unambiguous definition of the study population; 3) the choice of valid and responsive outcome measures, i.e. measures able to detect changes over time if a real and significant change in the patients' clinical condition has occurred; and 4) a design that best allows the comparison by minimizing biases (table 2). The following discussion addresses these considerations.

Study intervention: comparison of ICS. In comparing ICS, the investigators should first take into account the pharmacodynamic and pharmacokinetic properties of the drugs under study.

Dose-response and plateau effect of ICS. It has been established that there is generally an increasing effect of ICS with increased dosing (dose-response effect). For example, TO0G00D and co-workers [28, 29] determined that increasing doubling-doses of beclomethasone dipropionate $\left(200-1,600 \mu \mathrm{g} \cdot\right.$ day $\left.^{-1}\right)$, inhaled budesonide (800-3,200 $\mu \mathrm{g} \cdot$ day $\left.^{-1}\right)$ or prednisone tablets $\left(7.5-40 \mathrm{mg} \cdot\right.$ day $\left.^{-1}\right)$ every 2 weeks for 6-8 weeks, provided a dose-response improvement in symptoms, expiratory flows and bronchodilator needs. This provides an opportunity to compare different doses of two agents and different degrees of severity of asthma. Nevertheless, there is a paucity of data assessing comparative dose-response relationships of ICS in terms of potency. A dose-response examination is required to

Table 2. - Difficulties with clinical trials of inhaled corticosteroids (ICS)

\begin{tabular}{ll}
\hline Study intervention & Dose-response and plateau effect of ICS \\
& Different inhalation devices used \\
Study populations & Insufficient number of patients to achieve \\
& sufficient statistical power \\
& Asthma too well-controlled to show a \\
& difference \\
& Sufficiently unstable asthma required to \\
& allow clinical improvement \\
& Asthma destabilization associated with \\
& potential risks \\
& Different efficacy parameters and methods \\
of analysis & Undefined minimal clinically important \\
difference & Irrelevant outcomes \\
& Lack of responsiveness of outcome \\
& measures \\
Use of crossover design & Insufficient duration of washout period in \\
crossover trial & Insufficient duration of treatment \\
&
\end{tabular}

identify whether a dose of new drug is similar or different to one dose above and one below. Looking at the slope and position on the dose-response curve may provide information on the effects of different doses. Most comparisons between budesonide and beclomethasone have, however, used single-doses of each drug [27].

With regard to potential problems associated with comparative studies of ICS, one is the presence of a "plateau" over which increasing doses cause minimal improvement in asthma [5]. Although, in most subjects, this "plateau" seems to appear at doses greater than the equivalent of $1,000-2,000 \mu \mathrm{g}$ of beclomethasone, it may vary according to the subjects selected, their steroid responsiveness and over time [27]. Problems may, therefore, arise if the doses used are on the plateau of the dose-response curve, making it difficult to detect intertreatment differences.

Another factor that may influence results is the frequency of dosing. A corticosteroid given at 4 doses $^{-}$day $^{-1}$ may offer better results than with less frequent dosing, for a given total daily dose, although most subjects will be well controlled with twice, or even once, daily doses of ICS [30, 31]. Furthermore, according to chronopharmacological studies, the time of the day the agent is given should also be considered. It has been suggested that corticosteroids were more efficacious when given in the afternoon than in the morning [32]. In this regard, a single total daily dose administered at the end of the day offered a similar degree of asthma control as a twice daily dose in stable mild to moderate asthmatic subjects, although this has also been suggested with single morning doses of budesonide or fluticasone [30, 31, 33].

As indicated elsewhere in this report, the different delivery systems currently available for inhaled medications may influence bioavailaibility and efficacy of the agents tested and are another factor that should be considered in the design of any trial of ICS. The type of device or the addition of a spacer to a metered-dose inhaler may affect drug deposition [34]. As the study question is usually whether one corticosteroid is more potent than another, any difference in study outcome should not be explained by a difference in their mode of administration.

Selected examples of comparisons of different ICS. The aim of this report is not to provide an exhaustive review of the studies assessing the comparative efficacy of ICS. The primary intention is to stress the difficulties and considerations that need to be taken into account in doing such comparisons, using specific examples (although not all were necessarily designed to identify bioequivalent or relative potency) to illustrate what has been done up to now and how these investigations can be improved and better standardized. Three selected comparisons are given below: 1) Comparison of beclomethasone and budesonide. Many studies have been conducted to assess and compare the therapeutic efficacy of beclomethasone dipropionate and budesonide, in both adults and children. Reviews of these results have been published $[27,35,36]$. Most of them involved doses $ð 800-1,000 \mu \mathrm{g} \cdot \mathrm{day}^{-1}$. The different evaluations suggest that budesonide is at least as effective as beclomethasone throughout the whole range of dosing [3749]. The drugs were, however, sometimes administered by different inhaler devices or without a washout period, making the comparative efficacy of the two agents difficult to assess. 
2) Comparison of beclomethasone and fluticasone. Doseranging studies have shown a dose-related improvement in asthma control with fluticasone propionate and increased potency of fluticasone compared to beclomethasone in terms of improvement of pulmonary function [50-55]. A 2:1 equivalence of fluticasone over beclomethasone has been suggested, based on the observation of maintenance of the same degree of asthma control with a half-dose of fluticasone compared to beclomethasone [56, 57]. Similar doses provided a better improvement over $1 \mathrm{yr}$ in asthma severity and reduction of asthma exacerbations with fluticasone than beclomethasone.

3) Comparison of budesonide and fluticasone. The equivalence of budesonide with fluticasone is still controversial $[58,59]$.

Study populations: which patients should be studied? The main site of action of ICS is considered to be on eosinophilic airway inflammation. Accordingly, the clinical or physiological improvements have been associated with a reduction of this inflammatory process $[60,61]$. The degree of airway inflammation varies significantly between subjects and is difficult to study clinically by procedures such as bronchial biopsy and bronchoalveolar lavage (BAL). In the future, it may be studied successfully by less invasive techniques such as induced sputum [6264].

Up to now, asthmatic patients in clinical trials have most often been enrolled on the basis of clinical definitions related to the severity of the disease. Recently, CockCROFT and SWYSTun [65] underlined the current confusion that exists between the concepts of "asthma control" and "asthma severity". "Asthma severity" is defined in several ways. On the one hand, it has traditionally been defined according to a combination of features such as symptoms, medication requirements, physiological abnormalities and morbidity. These last, however, mostly describe a lack of asthma control and severity can be better defined according to the anti-inflammatory medication required to achieve asthma control, although we should keep in mind that steroid-responsiveness can modulate this. Control of asthma may, therefore, be defined according to the presence or absence of asthma symptoms and the impact of the disease on the functional status of patients' functional status [3]. Thus, severe asthma may be well controlled, with minimal symptoms and excellent pulmonary function; on the other hand, mild asthma may be uncontrolled or poorly controlled. Achieving disease control and reducing its severity represent different objectives although they are closely related.

To study the effect of ICS on the control of asthma, however, the disease should be slightly uncontrolled in order to allow clinical improvement to be detected. There should probably be eosinophilic airway inflammation, as detected by induced sputum. It may be difficult to compare the effects of two drugs if the degree of control is different from one group to another or if patients are very poorly controlled, in which case marked improvements in both groups when ICS are added or increased may mask a difference. The possibility of destabilizing asthma before the study is associated with potential risks that may be considered unethical, unless performed as progressive withdrawal with close follow-up. When the trial is performed in only mild to moderately uncontrolled asthma, even if subjects have been like this for weeks or months, close follow-up is required, to detect any worsening that would require rapid intervention. Placebo-comparative studies may not be possible unless the asthma is only mildly uncontrolled, as it is considered unethical to leave more severely uncontrolled asthmatics without anti-inflammatory drug treatment.

The issue of sample size of clinical trials. The inclusion of heterogeneous populations of asthmatic patients (allergic and nonallergic asthma; children and adults; severe and mild asthma) in clinical trials would enhance the gener-alizability of the findings. However, the more heteroge-neous the study population, the larger the measures of dispersion of the clinical outcomes, with the consequent increase in sample size required to detect any difference or to demonstrate that the drugs under study are equivalent.

Investigators planning ICS trials are usually interested in demonstrating the equivalence of therapies, that is the degree of similarity in therapeutic effects of two or more drugs [66]. In designing such trials, attention must be paid to the type II $(\beta)$ error, that is the probability of falsely accepting the null hypothesis when a difference truly exists. In interpreting the reports of such clinical trials, nonsignificant $\mathrm{p}$-values do not inform the clinician about the type II error. Many authors have rather suggested that presenting confidence intervals is a better approach to equivalence testing of drug formulations [26, 67, 68].

The confidence interval around a mean represents the range of values that are plausible for the population [69]. For instance, let us consider the difference in forced expiratory volume in one second (FEV1) following a randomized double-blind crossover trial of inhaled fluticasone propionate versus beclomethasone dipropionate in 21 asthmatic patients [54]. After the two 6 week treatment periods, the difference was $60 \mathrm{~mL}$ favouring fluticasone propionate. The $95 \%$ confidence interval for the population difference mean was from $-80 \mathrm{~mL}$ (that is $80 \mathrm{~mL}$ favouring beclomethasone dipropionate) to $195 \mathrm{~mL}$ (that is $195 \mathrm{~mL}$ favouring fluticasone propionate). Simply put, this means that if a number of similar trials were carried out in different samples of patients from the same population, then the mean difference would fall, in the long run, within this interval $95 \%$ of the time. A larger sample size would have reduced the width of the confidence interval in producing a better estimate of the "true difference". Ninety five percent confidence intervals are most often selected because they correspond to the usual 5\% level of statistical significance.

Since power is exclusively a pretrial concept, it should not play any role once the data have been collected. Instead, the confidence interval around the score difference should address the question of significance of negative results [68]. In equivalence trials, before accepting the null hypothesis, the confidence interval of the differences in clinical outcome should fall within predetermined limits corresponding to values usually regarded as clinically non-significant [70].

As a correlate, in some studies, particularly when large groups of subjects are enrolled, small differences between drugs may become highly significant. However, these differences might not be meaningful in clinical practice. Some authors have arbitrarily determined clinical significance of pulmonary function parameters but these may vary from 
one to another. The same issue also applies to funding agencies and formularies, which have to determine if the differences observed between a new agent and current standards are sufficiently different to warrant approval, sometimes at a higher cost [70].

Study design: on the use of crossover design. Recent overviews of clinical trials of inhaled steroids in asthma have also demonstrated that the crossover design has been the most commonly used by investigators [27]. In crossover trials, subjects serve as their own control, thereby reducing error variance [71]. Consequently, fewer patients are generally needed as compared to the randomized parallel-group controlled trial. Lous et al. [71] have considered a number of factors that determine the effectiveness of the crossover design. The major concern with the crossover design in asthma trials is the carryover effect: the therapeutic effects of the first treatment may persist during the administration of the second. In asthma trials, investigators have tried to overcome the problem of carry-over effect in several ways: either a wash-out period has been introduced between the treatment periods, or the statistical analysis has concentrated on the data collected at the end of each treatment period.

Nevertheless, one could argue that crossover design is not optimal in investigating the effect of any anti-inflammatory drug in asthma for several reasons. Firstly, asthma is, by definition, a disease characterized by fluctuations of symptoms and physiopathological manifestations [3]. This also applies to parallel group studies, but the influence of these changes may be more significant in studies with a crossover design. Secondly, inflammatory changes and clinical manifestations can be partially or even, in mild cases, completely suppressed with anti-inflammatory drugs [72]. Thirdly, and most importantly, ICS may have persistent effects after cessation of the treatment for variable periods of time, their duration of action not being well characterized $[73,74]$. Consequently, on a theoretical basis, parallel-group should be preferred over crossover designs. The potential problems with the crossover design should be weighed against the disadvantages of a parallel group design, particularly with regard to the issue of sample size, which is typically larger in parallel group design.

Study outcomes: which parameters should be measured? Symptoms, $\beta_{2}$-agonist use and expiratory flows. Symptoms, $\beta_{2}$-agonist use and expiratory flows are among the most frequently used parameters to evaluate the efficacy of ICS (table 3) [74]. Symptoms are measured during the day and night, on different scales. Objective measurement of expiratory flows should be used. These include the ambulatory measurement of PEF comparing morning, evening and diurnal variation. Spirometry obtained in the laboratory, or more recently from computerized devices, may be obtained. The use of rescue medication ( $\beta_{2}$-agonist use) is considered another good marker of asthma control [75]. Each of these outcomes has its own clinical relevance for both the asthmatic patient and the physician. The choice of a clinical outcome as the primary endpoint in clinical research is still a matter of controversy.
Table 3. - Common asthma outcomes measured to assess efficacy of inhaled corticosteroids

\begin{tabular}{ll}
\hline $\begin{array}{c}\text { Respiratory } \\
\text { symptoms }\end{array}$ & $\begin{array}{c}\text { Type of symptom: cough, breathlessness, } \\
\text { chest tightness, sputum production, } \\
\text { wheeze } \\
\text { Chronology: night-time, daytime }\end{array}$ \\
Expiratory flows & $\begin{array}{l}\text { Intensity: different scales... } \\
\text { Peak expiratory flow: morning, evening, } \\
\text { diurnal variation }\end{array}$ \\
Spirometry & $\begin{array}{l}\text { Expiratory flows } \\
\beta_{2} \text {-agonist use }\end{array}$ \\
Rescue medication & Chemical agents: (histamine/ \\
Airway & methacholine, AMP, adenosine) \\
responsiveness & $\begin{array}{l}\text { Physical stimuli (exercise, cold air); } \\
\text { Assessment of different domains }\end{array}$ \\
Quality of life & ED visits, hospital admissions \\
Morbidity & Reduction in health care costs \\
Socioeconomic & \\
variables & \\
\hline AMP: adenosine monophosphate; ED: emergency department.
\end{tabular}

Ideal measure outcomes to be used in clinical trials should be valid and responsive. The responsiveness of an instrument refers to its ability to detect a real change in the patient's condition over time, even when it is small [76]. Changes should be detectable over a reasonably short period of time in order to limit the study period and the high drop-out rates associated with long clinical trials. The responsiveness of an outcome measure also determines the sample size needed to detect a significant change.

From the perspective of the patients, health-related quality of life (HRQoL) is the most relevant outcome. However, the correlation between health status reported by patients and physiological measures is not always good [77]. As compared to chronic obstructive pulmonary disease (COPD) [78], the objectives of asthma therapy may not only be to relieve current symptoms. Indeed, from the perspective of the physician, physiological outcomes such as airway hyperresponsiveness may help to predict clinical outcome [79]; this, in addition to the ability of many patients to adapt their lifestyle to reduce asthma symptoms and the impact of the disease on their day-to-day life [80], makes physiological outcomes as relevant as quality of life when establishing goals of treatment.

Airway responsiveness. Long-term administration of ICS reduces airway responsiveness [81-85]. Assessment of airway responsiveness, either with exercise, cold air, histamine/methacholine or adenosine monophosphate (AMP) challenges, may be useful to compare the efficacy of ICS. More studies are needed to examine dose-response effects of ICS on airway responses to these stimuli [86] (see Bronchoprovocation tests section).

Proposal for studies of comparative efficacy of ICS from clinical trials. Elements of an "ideal" study group to determine comparative efficacy using clinical trials are presented in table 4. They include mildly uncontrolled asthma and, preferably, steroid-naive subjects; there should be sufficient room for improvement but not marked lack of control that may be deleterious for the subject and would allow almost any compound with some degree of activity to induce significant improvements. There should be airway inflammation on which ICS can act. Sample size should be large enough to reduce the magnitude of 
Table 4. - Elements of an "ideal" clinical trial to compare efficacy of inhaled corticosteroids

Mildly uncontrolled asthma

Preferably steroid-naive subjects

Double-blind, randomized, parallel group study

Sample size sufficient to avoid type II group study

Includes physiological (e.g., airway responsiveness) and quality of life measures

Grades-doses trial with at least three doubling-doses of each corticosteroid plus, ideally, another one if the drug is new Presence of sufficient airway inflammation (eosinophilic)*

*: may be assessed by noninvasive techniques such as induced sputum analysis

type II error. With regard to the best comparison parameters, physiological outcomes and HRQoL measures should coexist. Airway responsiveness to AMP may possibly afford better sensitivity than methacholine responsiveness to detect a difference between two ICS, although this should be studied further. Since the objective of most trials is to demonstrate the equivalence of ICS, the interpretation of any negative clinical trials should focus on the magnitude and limits of the confidence interval around the mean difference in clinical outcomes in relation to what is usually considered as the minimal clinically important difference. Ideally, the study should be randomized, doubleblind, graded-doses trials, with at least three doubling doses of each corticosteroid considered to be equivalent. Parallel-group should be preferred over crossover trials, as they avoid the risk of a persisting effect of the first treatment or change in baseline parameters from one period to the other.

\section{Bronchoprovocation tests}

Bronchoprovocation tests are valuable in both clinical evaluation and research studies in asthma. It is hypothesized that the bronchoprovocation laboratory may provide a method for evaluating relative potency of inhaled corticosteroids. There are few data to support this hypothesis. This review, therefore, is largely theoretical.

Airway responsiveness. Airway responsiveness is measured using many different stimuli to provoke bronchoconstriction [87]. The stimuli can be initially divided into selective and nonselective (table 5). Selective stimuli will provoke bronchoconstriction in only some asthmatic subjects and include sensitizing agents (allergens, low molecular weight chemical sensitizers) and nonsensitizers (acetyl salicyclic acid (ASA), nonsteroid anti-inflammatory drugs (NSAID) and, perhaps, food additives). The nonselective stimuli will, in theory, provoke bronchoconstriction in all asthmatic subjects. The terms "nonallergic" and "nonspecific" have also been used. Recently, it has been suggested that the nonselective stimuli might be more appropriately divided into "direct" and "indirect" [88]. Direct stimuli provoke bronchoconstriction by acting directly on mediator-specific receptors on smooth muscle, and include histamine, methacholine and other muscarinic agonists, and probably arachidonic acid metabolites. The indirect stimuli provoke bronchoconstriction through intermediate pathways such as mast cell mediator release, neurological reflex, etc. The physical stimuli and some of the chemical stimuli (AMP, $\beta$-adrenergic blockers, others) are
Table 5. - Stimuli used for bronchoprovocation

\begin{tabular}{ll}
\hline \multicolumn{1}{c}{ Nonselective stimuli } & \multicolumn{1}{c}{ Selective stimuli } \\
Chemical & Sensitizers \\
Histamine & Inhaled allergens (IgE) \\
Muscarinic agonists & Ingested allergens (IgE) \\
(e.g., methacholine) & Low molecular weight \\
& sensitizers
\end{tabular}

$\beta$-adrenergic antagonists $\alpha$-adrenergic antagonists

Prostaglandin $(\mathrm{F} 2 \alpha)$

Leukotrienes $\left(\mathrm{C}_{4}, \mathrm{D}_{4}, \mathrm{E}_{4}\right)$

Platelet activating factor

Bradykinin

Tachykinins

Seratonin

AMP

Nonmediator (e.g., $\mathrm{SO}_{2}$ )

Physical

Exercise

Cold air

Nonsensitizers

ASA and NSAIDs

Food additives

(metabisulphate)

Hyperventilation

Possibly some food

Distilled water aerosol ("fog")

hypersensitivities

Hypertonic aerosols

"Inert" dusts

IgE: immunoglobulin E; AMP: adenosine monophosphate; ASA: acetyl salicyclic acid; NSAIDs: nonsteroid anti-inflammatory drugs.

probably indirect. Although this classification is generally applied to the nonselective stimuli, all of the selective stimuli (e.g., allergen) also involve indirect mechanisms.

ICS and airway responsiveness. Single doses of corticosteroids, either inhaled or oral, exert no influence on nonselective airway responsiveness [89]. By contrast, regular dosing with ICS has a marked influence on airway responsiveness [81-83, 85, 90-99], hypothesized to be due to reduction in airway inflammation [100]. The improvement in airway responsiveness is variable from study to study and may well depend on patient population, dose of corticosteroid and duration of treatment.

Generally, improvement in histamine or methacholine provocative dose or concentration causing a $20 \%$ fall in FEV1 (PD20 or PC20, respectively) values in the range of one to two doubling concentrations or doses is reported with a short-term corticosteroid treatment (1-6 weeks). Studies of longer duration suggest that the improvement in airway responsiveness may continue for several months or longer. The greatest improvement in airway responsiveness was shown by Woolcock et al. [92] over a period of 18-24 months. This marked improvement could be partly explained by the fact that at the time of enrolment in the study the subjects had uncontrolled asthma, although the improvement continued over a few months, when asthma was probably better controlled. Nevertheless, a study such as this is of necessity when uncontrolled and other factors may play a role in the improvement (environmental control, natural history, other medications, etc.). It is impossible from the literature to assess whether or not there is a dose-response for the effect of corticosteroids on airway responsiveness to histamine or methacholine. There appears to be a relationship between the response and the duration of treatment. 
Airway responsiveness to indirect, nonselective stimuli also improves with regular corticosteroid treatment [54, 101-108]. There are a few studies that critically address corticosteroid responsiveness of indirect stimuli compared to that of the direct stimuli; these studies suggest a similar degree of improvement [54, 105-108].

ICS and airway response to allergens. The airway response to allergen is much more complex than the response to nonselective stimuli [109]. Allergen inhalation provokes an early asthmatic response (EAR) that is maximal 10-30 min after exposure and resolves within 90-120 min. Following spontaneous resolution of the EAR, about $50 \%$ of subjects with positive allergen challenges develop a late asthmatic response (LAR). The LAR is a recurrence of airflow obstruction developing 3-4 and 8-12 h after the allergen exposure. The late response is associated with airway inflammation and increase in nonselective airway responsiveness.

Much like the airway response to non-selective stimuli, the EAR is not affected by a single dose of corticosteroid [110-113]. By contrast, treatment with corticosteroids ranging from 1 week to 2 months can result in a major inhibition of the EAR [99, 112, 114-116]. This inhibition may be partly the consequence of the improvement in airway responsiveness. However, the inhibition of the EAR is greater than the inhibition of airway responsiveness [99], and is likely due to the anti-inflammatory effect, probably the specific result of a reduced number of airway mast cells.

By contrast the LAR can be inhibited by a single dose of ICS administered either before the allergen challenge $[110,111,113,117]$ or in the interval phase between the EAR and LAR at $2 \mathrm{~h}$ after allergen challenge [118].

Laboratory models for relative potency of inhaled corticosteroids. There are few if any data available to assess the role of bronchoprovocation with nonselective stimuli, either direct or indirect, as a model for testing relative potency of ICS. In one study, as yet published only as an abstract, methacholine PC20, was a secondary endpoint (allergen being the primary endpoint); three different doses of budesonide were effective at improving the methacholine $\mathrm{PC} 20$ by almost a doubling concentration after 6 days of treatment and, there was no trend for a doseresponse [119].

More investigators have recently attempted to utilize allergen challenge as a model for testing relative potency of ICS [120-122]. The first published paper was, unfortunately, not randomized. Increasing doses of ICS were administered at 1 week intervals in sequentially increasing doses [120]. The resulting apparent increase in inhibition of the allergen-induced EAR may well have related to the increasing duration of treatment rather than to the increasing doses administered.

Three other studies have been published, one using a 1 week treatment and examining the influence on the EAR [119], and two using single doses and looking at the influence on the LAR [121, 122]. All three investigations showed marked efficacy of the inhaled corticosteroid used in these models but very little dose-response relationship, suggesting that the dose-response had reached a plateau in these subjects at low doses.
Conclusions. At present there are insufficient data available to exclude the use of the bronchoprovocation laboratory in comparing relative potency of ICS. The limited available data suggests that the beneficial effects of ICS on airway responsiveness (either direct or indirect stimuli, both sensitizing and nonsensitizing) tend to plateau at low doses. This may be partly due to the use of a homogeneous and fairly mildly patient population. Further studies may prove helpful. Such studies could use modifications such as studying: different stimuli; a wider range of asthma severity; a lower dose range of the inhaled corticosteroid; shorter treatment periods; and longer treatment periods.

\section{Steroid reduction model}

In clinical practice, guidelines suggest that uncontrolled asthma should be treated with appropriate doses of glucocorticoids to achieve the least symptoms, the least need for $\beta_{2}$-agonist and the best maximal expiratory flow rates [3]. At the same time, an inhaled short acting $\beta_{2}$-agonist is used only when needed. Once the best results are achieved, the dose of corticosteroid is reduced to identify the smallest that will maintain these. Therefore, it seems possible that the in vivo bioequivalence or relative potency of ICS might be identified by comparing the dose required to maintain the best results.

One study was successful in a large sample of 217 children who required regular treatment with inhaled budesonide from a pMDI and in whom the minimal effective dose was known to be 800 or $400 \mu \mathrm{g} \cdot$ day $^{-1}$ [123]. The children entered a randomized double-blind parallel group trial in which they received half the dose of budesonide delivered by Turbuhaler (Astra) or fluticasone propionate delivered by Diskhaler (Glaxo Wellcome). At intervals of 5 weeks, the dose was further reduced by $50 \%$ until deterioration of asthma control was seen. The minimal effective dose was $188 \mu \mathrm{g}$ for budesonide Turbuhaler and 180 $\mu \mathrm{g}$ for fluticasone Diskhaler, i.e., the two drugs inhaled from the two delivery systems were equally effective.

In another unpublished study, 12 adults with asthma were involved in a randomized, double-blind, crossover trial. The subjects were considered to require $800 \mu \mathrm{g}$ of inhaled budesonide via Turbuhaler to control their asthma. The dose of budesonide was reduced by 100 per week or 200 $\mu \mathrm{g} \cdot$ week $^{-1}$ until there was an exacerbation of asthma. The exacerbation was then controlled by increasing the dose to twice the starting dose for 2 weeks or longer until the asthma was controlled again and then reducing the dose to the starting dose for 2 weeks before reducing the budesonide in the alternative way. The outcomes were symptoms score, need for $\beta_{2}$-agonist, mean morning PEF in the last 5 days, FEV1, proportion of eosinophils in induced sputum, peripheral blood absolute eosinophil count and serum eosinophil cationic protein (ECP) level at clinic visits. The study was unsuccessful but identified a number of issues to be considered in future trials, including the confounding influence of natural exacerbating factors such as intercurrent exposure to inhaled allergens or respiratory infections, whether to use a single or double blind scheme for reduction of ICS, whether to use a parallel group or crossover design, the amount of steroid dose to reduce on each occasion and at what intervals, and the definition of an exacerbation (table 6). 
Table 6. - Difficulties encountered with the steroid-reduction model

Confounding influence of natural exacerbating factors Allergens

Respiratory infections

Related to the study design

Single or double blind scheme of reduction of ICS

Parallel group or crossover design

Amount of steroid dose to reduce on each visit

Intervals of reductions

Criteria defining an exacerbation

Based on symptoms and bronchodilator needs Based on pulmonary function

ICS: inhaled corticosteroids.

Confounding factors. It is relatively easy to minimize the influence of allergic factors by selecting subjects who will not be exposed to allergen during the study. However, it is more difficult to recognize respiratory infections, which will increase symptoms and possibly decrease expiratory flow rates and produce an exacerbation that is not necessarily due to the reduction of steroid dose. The recognition of possible infections is, thus, an important issue when exacerbations occur. This can probably be achieved by examination of induced sputum cell counts [64, 124, 125]. Exacerbations due to reduced steroid dose are associated with an increase in the proportion of sputum eosinophils. Infections are characterized by an increase in the total cell number and differential cell count of neutrophils without an increase in the proportion of eosinophils. Subjects with such an exacerbation should be withdrawn from the study.

Study design. A single blind reduction of the dose of steroid means that the patient and physician are expecting an exacerbation. An increase in symptoms may then be easily misinterpreted. It is, therefore, important to make the steroid reduction double-blind.

A crossover study has the advantage of needing few subjects while a parallel group study has the disadvantage of needing more. However, a crossover study has the disadvantage of being longer and of increasing the likelihood of confounding factors and of reducing subject compliance because of the long duration. A parallel group study, is therefore, probably the preferred design. The sample size probably does not need to be large, provided that the various difficulties are considered, minimized and evaluated when necessary.

The optimum method of reducing the dose of inhaled steroid has not been established. At present, a common method is to reduce the dose by half. The optimum intervals between the reduction of each dose has also not been determined. In the successful study of AGERTOFT and PEDERSEN et al. [123], the dose was reduced every 5 weeks. In the unsuccessful crossover study reported above, in which the daily dose of budesonide Turbuhaler was either reduced by 100 or $200 \mu \mathrm{g} \cdot \mathrm{week}^{-1}$, the exacerbating dose was the same in both arms. This result suggests that the reductions in dose should be made at no less than every 3 weeks.

Definition of an exacerbation. The definition of the exacerbation must be planned carefully. It must not be so mild as to be misinterpreted or so severe as to cause the subjects too much discomfort. While symptoms are usually a more sensitive indicator of an exacerbation, they are non- specific $[62,126]$. Objective criteria are required, such as a fall in FEV $1>10 \%$. It is advisable also to ensure that there is an increase in induced sputum eosinophils associated with reduction of ICS to confirm that the inflammation of the exacerbation is eosinophilic and not noneosinophilic due to a confounding cause.

Conclusion. In conclusion, the steroid reduction model to investigate bioequivalence or relative potency of inhaled steroids can be successful, but is difficult. Determining the optimum design requires further investigation.

\section{Recommendations with regard to efficacy}

There are five principal recommendations:

1) Further studies should be done to determine what is (or are) the best method(s) to compare inhaled corticosteroid (ICS) preparations.

2) When comparing the safety of ICS, the following factors should be taken into consideration: nature of the drug; mode of administration; type and severity of asthma; control population; concomitant treatments; study design; and the choice of parameters considered for comparison.

3) Bronchoprovocation may be useful to compare the relative potency of ICS, although their beneficial effects on airway responsiveness tend to plateau at low doses. Further studies are required and should consider: different stimuli; a wider range of asthma severity; a lower dose range of ICS; and shorter and longer treatment periods.

4) The steroid-withdrawal model is a possible method to compare the relative potency or bioequivalence of ICS. However, this type of study is demanding and the optimal design requires further evaluation. A best test may be a randomized placebo-controlled parallel group trial in which the steroid dose is reduced (e.g. by $25-50 \%$ ) in one group at intervals of about 4 weeks. Two important considerations are a predetermined definition of an exacerbation and the recognition of confounding events such as respiratory infection or allergen exposure.

5) Clinical trials may allow significant differences between two treatments to be determined if the sample size is large enough when comparing the relative potency of ICS. Subjects with mildly uncontrolled asthma (with induced sputum eosinophilia?) who are preferably not on steroid treatment should be selected. The outcomes should include physiological and HRQoL measures. Airway responsiveness to different bronchoconstricting agents may be more sensitive than other physiological parameters but this should be further assessed, particularly with AMP. Effects on markers of inflammation such as induced sputum or exhaled nitric oxide measurements should be explored. The study design should be a randomized, double-blind, graded doses trials (ideally covering a fourfold range in dose), with ideally at least three doses of each corticosteroid. Parallel-group are preferred over cross-over trials, as they avoid the risk of carry-over effect.

\section{Assessing systemic bioequivalence and relative safety}

Regulatory decision-making requires a standardized procedure for comparing the safety of new generic ICS versus formulations previously approved for asthma treatment. 
The systemic effects of ICS on the HPA axis and bone turnover provide a clinically relevant pharmacodynamic basis for making such comparisons. The graded dose assay model offers the most versatile system for generating the required data.

\section{Investigative approach}

Objectives. The primary goal is to determine whether the generic test drug (TD) is systemically equivalent to a reference standard drug (SD). This involves the calculation of a relative potency for the two drugs, or alternatively a response ratio, to quantify their respective activities.

Outcome. From these data a categorical decision is derived, "approval" or "rejection", depending on whether the confidence interval for a comparison of the mean responses to the two drugs satisfies established criteria.

Locale. Single or multicentre studies are feasible. The latter provide a basis for validating the estimates of bioequivalence obtained by different groups of investigators, and thereby strengthen the regulatory decision.

Drugs. Graded doses of the TD (in this case, a generic ICS) are compared in vivo with the same labelled doses of an SD for which long-term safety data are available, e.g. beclomethasone or budesonide.

The TD and SD must be the same qualitatively and quantitatively $( \pm 5 \%)$ in terms of their active and inactive ingredients including the propellant mix in the pMDI. The delivery devices and their in vitro performance characteristics must be the same or very similar in terms of factors such as the particle size distribution and the velocity of the aerosol plume emitted from the valve. Disparities in any of these factors may bias the comparison by altering the mean particle size, intrapulmonary drug delivery and/or regional deposition of one of the drugs.

The inclusion of a "vehicle control" (placebo) provides a measure of the intrinsic variability of the response index, and confirms that the test doses were sufficiently large and intrapulmonary delivery sufficiently efficient to evoke systemic responses to each drug.

Test subjects. Healthy normal test subjects are preferred over asthmatic patients for safety testing in order to obviate the potentially confounding effects of past or current steroid therapy, and variability in the degree of airways inflammation and obstructive impairment which could act to reduce the power of the assay.

Milieu. After documenting normal values for the response indices to be measured, and randomly assigning the test subjects in balanced blocks to the proposed treatment sequences (see table 7 for example), some experts advise that the subjects be admitted to an investigative facility 48 $\mathrm{h}$ prior to starting the treatments. This is done to standardize the hours of recumbency and sleep versus wakeful activity for the group and stabilize their circadian HPA axis rhythm for two nights prior to treatment, thus reducing the variance of the response index and maximizing the statistical power of the assay.

Use of inhalation device. During the initial $48 \mathrm{~h}$ in the investigative facility, each subject is trained in the procedure appropriate for the particular inhalation device to be used to deliver the ICS. It is essential to optimize and standardize the inhalation technique for both drugs in order to avoid potential bias due to differences in intrapulmonary drug delivery.

Normally, inspiration is immediately followed by a mouth wash and expectoration of any orally retained drug. However, for the purposes of this type of safety study, the mouth wash may be omitted at the discretion of the investigator so that the combined effects of gastrointestinal as well as pulmonary absorption of the drugs may be assessed.

Treatments. At least three dose levels of active drug are administered in addition to a placebo. The dose levels are selected with a view to achieving statistically significant mean responses on the steep part of the curve. To ensure this, a dose range of three or preferably fourfold is desirable, embracing the upper limit of the range approved for multiple dosing of the SD in clinical practice. The steeper slope associated with the use of high doses increases the statistical power of the assay [127]. This may be partly offset by an accompanying increase in variance with the larger response [127].

Since the drugs being compared share the same pharmacokinetics and dynamics, single dosing may be used rather than multiple dosing. With the exception of fluticasone, in which an exceptionally long receptor-ligand binding time and terminal plasma half-life after absorption is coupled with very high lipophylicity [128, 129], most of the effect of antiasthmatic ICS on the serum cortisol (SC)

Table 7. - A representative schedule for placebo $(\mathrm{PL})$, two active drugs and three doses

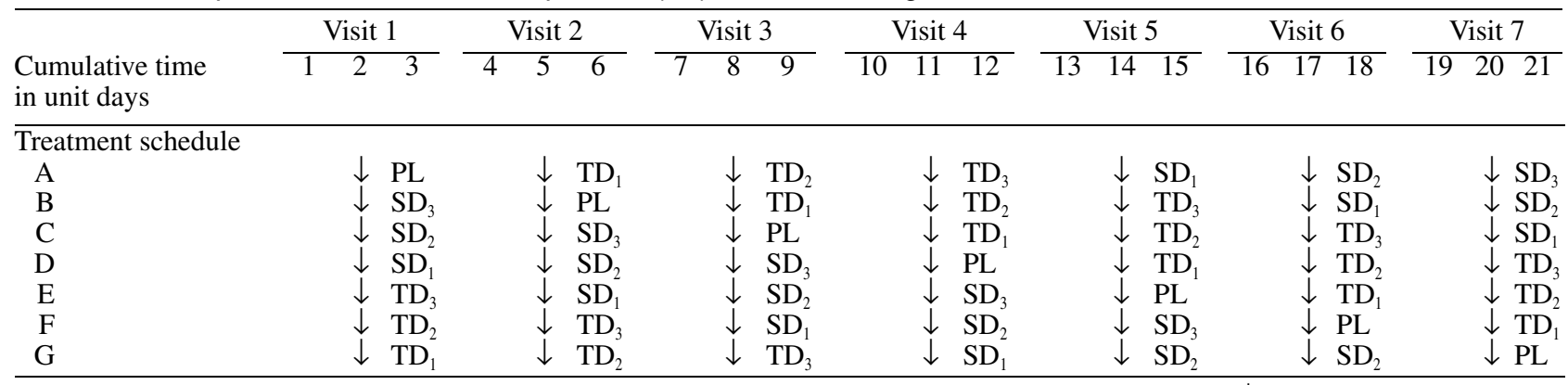

There is a washout period between visits. A single dose is given at 22:00 $\mathrm{h}$ on the second day of the visit ( $\downarrow$ ), and specimens collected through the next $24 \mathrm{~h} . \mathrm{TD}_{1}, \mathrm{TD}_{2}, \mathrm{TD}_{3}$ : test drug at low, intermediate and high dose, respectively; $\mathrm{SD}_{1}, \mathrm{SD}_{2}, \mathrm{SD}_{3}$ : standard drug at low, intermediate and high dose, respectively. 
concentrations expressed as area under the curve (AUC) averaged over $24 \mathrm{~h}$ ( $\mathrm{SC} 0-24 \mathrm{AUC})$ is evident after the first dose, and the variance of the SC0-24 AUC response to most ICS (excluding fluticasone) is essentially the same with single or multiple dosing (table 8) [130].

To maximize the effect of the ICS on HPA function, the single dose is administered at 22:00 h. All doses should be administered under the supervision of a trained technician.

Design. Attention is required to the principles that govern the design, conduct and analysis of drug trials which have as their primary objective, the assessment of between- drug equivalency as opposed to differences [131-133].

Table 7 illustrates an example of a balanced cross-over schedule of treatments with washouts between each dose. In this model, every patient receives each drug-dose combination once, each drug-dose combination is represented at each visit, and the seven treatment sequences are balanced throughout. The required duration of the washouts may be calculated from published data for the plasma half-life or half-time of the receptor-ligand complex of the particular ICS being tested. The washout should be Š48 h and long enough to ensure the plasma cortisol concentration at $08: 00 \mathrm{~h}$ is within $100 \mathrm{nM}$ of the baseline value established for each test subject prior to starting the test treatments.

Table 9 illustrates a cumulative dose-response model that offers a more expeditious alternative to the classical dose-response because the between-dose washouts are omitted. Such a model might prove practicable in this context, as it has in various clinical studies of ICS [29, 134, 135].

For multicentre studies, the treatments should be randomized separately by site, with equal numbers of test subjects at each site.

Response index. An index of HPA axis function and/or bone turnover may be measured. Given past experience with oral and systemic steroid therapy, the adverse effects of ICS drugs on bone may eventually prove to be more

Table 8. - Coefficients of variation for serum cortisol concentrations averaged over $24 \mathrm{~h}$ (SCO-24 AUC)

\begin{tabular}{lccc}
\hline & Placebo & $\begin{array}{c}\text { Active drug } \\
\text { single dose }\end{array}$ & $\begin{array}{c}\text { Active drug } \\
\text { multiple doses }\end{array}$ \\
\hline Mean* & 20.2 & 22 & 21.5 \\
Range & $17.2-27.3$ & $16.4-33.8$ & $12.4-28.7$
\end{tabular}

The values are coefficients of variation (sD/mean) expressed as percentages. *: averaged data for flunisolide, beclomethasone, triamcinolone acetonide and budesonide $(\mathrm{n}=12)$. Unpublished data, adapted with permission [130]. important clinically than their effects on the HPA axis $[136,137]$. Despite this, the HPA axis is currently preferred for safety studies of ICS because their effects on HPA function are more fully documented than those on bone.

HPA function may be assessed in terms of changes in the serum cortisol level at 07:00-08:00 $\mathrm{h}$, the $24 \mathrm{~h}$ urinary free cortisol output, the short or $6 \mathrm{~h}$, low or high dose tetracosactrin $(\mathrm{ACTH})$ tests, responsiveness to hypoglycaemic, pyrogenic, vasopressin or metyrapone challenge, or the SC0-24 AUC.

Recent experience indicates that the $\mathrm{SCO}-24$ AUC is equally or more precise and sensitive than the alternatives [138-143]. The improved precision increases the power of the assay, reduces the likelihood of underestimating the systemic activity of the TD (a desirable feature for safety studies) and reduces sample size requirements. Single doses of about $1.0 \mathrm{mg}$ of ICS show a mean co-efficient of variation (CV) for SC0-24 AUC averaging about 20\% (range 16-34\%) (table 8) [130]. Since most of the overall effect of a late evening dose of ICS on SC0-24 AUC is evident within the first $12 \mathrm{~h}$, it may prove practical to shorten the collection period.

Published comparisons between different ICS drugs in which SC0-24 AUC has been measured as the response index [141, 142] coupled with published formulae for trials designed specifically to assess therapeutic equivalence $[131,144]$ provide a basis for estimating the sample size needed for this particular application.

Laboratory analysis. To determine SC0-24 AUC, each subject's individual serum samples, obtained every $2 \mathrm{~h}$, may be pooled for analysis or analysed separately. Statistical considerations favour separate analysis, but in practice, the results have been found to correlate closely $(\mathrm{r}=0.97)$ [142].

The drug response may be expressed in terms of geometric or arithmetic means of the absolute values for cortisol and the percentage difference between placebo and active treatment values.

Statistical analysis. Analysis of variance (ANOVA) for repeated measures (e.g., Statistical Analysis System/General Linear Model; SAS Institute Inc., Cary, NC, USA) [145] is used to evaluate the suitability of the data for the parallel line method of estimating relative potency and to provide the basic quantities used in computing the estimate. Clear nonsignificance of the dose by drug interaction ( $p>0.10)$ and a significant linear effect of dose with no accompanying quadratic effect are essential requisites.

Table 9. - A representative schedule for a cumulative dose-response assay with placebo, two active drugs and three doses and a randomized, balanced crossover design

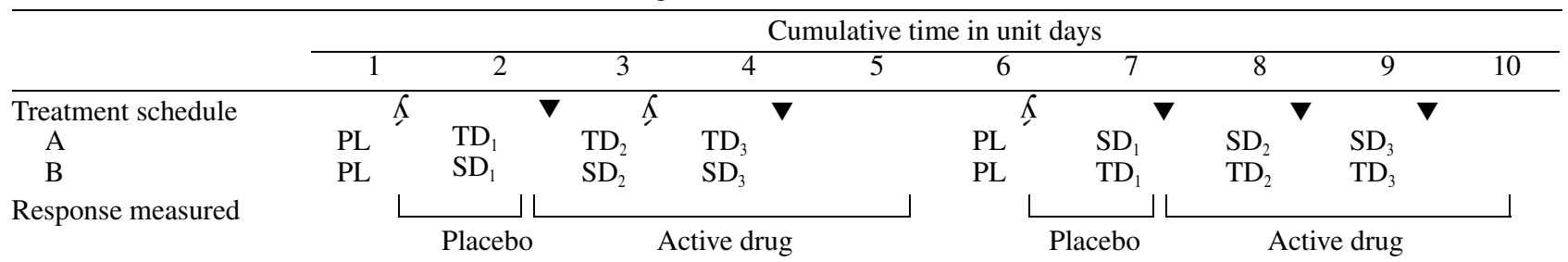

A single dose of placebo $(\Lambda)$ or active drug $(\boldsymbol{\nabla})$ is administered at 22:00 h. Specimens are collected over the next $24 \mathrm{~h}$. A washout period $\breve{S} 48 \mathrm{~h}$ is allowed between days 5 and 6 in the unit. For definitions see legend to table 7. 
Alternatively, the ratio of the mean responses to the two drugs may be computed. The analysis is performed on the natural logarithm of the response. Confidence limits for the ratio may be constructed by setting confidence intervals on the difference between the logarithms and inverting these limits to the ratio scale. The results so obtained are estimates of the ratio of geometric means.

The Food and Drug Administration (FDA) Division of Bioequivalence in the Office of Generic Drugs favours the use of response ratios to estimate bioequivalence rather than standard methodology based on the null hypothesis [14]. In practice, a recently published comparison between different ICS found that the response ratio for geometric means of SC0-24 AUC corresponded closely with the relative potency derived from graded-response curves in the same study [142].

Criterion for bioequivalence. The sensitivity of the assay, the sample size required to ensure adequate precision for the estimate of relative potency and the regulatory decision based on the estimate, all depend on the magnitude of the difference between the drugs that is deemed to be "clinically important".

A conventional criterion of $100 \pm 20 \%$ has been applied in systemic bioequivalence assessments of nonsteroidal drugs [14]. In the present context this would imply that, if the TD and SD are compared at milligram equivalent labelled doses and the systemic response to the TD proves, for example, to be equivalent to that of a $>20 \%$ larger dose of the SD, the difference between their respective activities is "clinically important".

It is not possible to substantiate this assumption from clinical data documenting the direct inhibitory effect of glucocorticoids on the HPA axis because the most important adverse outcome, stress-induced acute adrenocortical insufficiency, is rare among steroid-dependent asthmatic patients [146-148], and the risk of its occurrence is not accurately predictable from measures of HPA function [136, 149-151]. Furthermore, such tests are unreliable as predictors of the occurrence of the severe asthma exacerbations [29] or sudden death [152] that may complicate attempts at withdrawal from long-standing oral steroid usage under the aegis of inhaled steroid therapy [136].

On the other hand, steroid osteoporosis provides a suitable basis for validating the assumption, since this complication is relatively common among steroid-dependent asthmatic patients [153-156], potentially disabling, and the associated risk of fracture is quantifiable in terms of changes in bone density [157]. Thus, by relating the regression of spinal bone density on the daily dose of ICS as determined in beclomethasone and budesonide-treated adults [158], to published estimates of the incremental risk of fracture as a function of declining bone density [157], it may be calculated that a $20 \%$ excess in the systemic potency of the TD over the SD would be expected to increase the lifetime risk of fracture associated with any particular dose of ICS by about $20 \%$ [159]. Such an increment could reasonably be considered to signify a clinically important increase in risk.

Use of a surrogate index. Because the relatively high precision attainable with SC0-24 AUC is well documented, whereas similar data are sparse or lacking for the various indices of bone turnover, $\mathrm{SC} 0-24 \mathrm{AUC}$ is preferred at this time as a surrogate measure of risk. Its suitability for this purpose is supported by the statistically significant association observed between the numbers of steroid-treated asthmatic patients found to be at risk of fracture and the degree of their steroid-induced suppression of cortisol production [160]. However, SC0-24 AUC does not directly reflect the osteoporotic process upon which the estimate of clinically important risk is based, as discussed above. Also, the capacity of serum cortisol measurements to accurately predict serum osteocalcin production, each measured as the $24 \mathrm{~h}$ AUC, is not high $\left(\mathrm{r}=0.76, \mathrm{r}^{2}=0.58\right.$ [161]). Therefore, it would ultimately be desirable to add or substitute a measure of bone turnover, provided one or other of these can be shown to equal the sensitivity and precision attainable with SC0-24 AUC.

Regulatory interpretation. The process of deriving the regulatory decision from the estimated $95 \%$ confidence interval for the response ratio for TD/SD or their estimated relative potency may be summarized as follows:

1) If both limits of the estimated confidence interval lie within the interval $80-120 \%$ of the mean, the TD and SD are deemed to be equivalent.

2) If both limits of the confidence interval lie either below $80 \%$ or above $120 \%$, the TD and SD are deemed to be nonequivalent. (See also Simultaneous or separate assessment of safety and efficacy below).

3 ) If the confidence interval includes values both within and outside the $80-120 \%$ interval, the assay is deemed to be inconclusive. Further study may be recommended, particularly if the confidence interval is fairly wide and the ratio actually estimated lies within the range $90-110 \%$.

Practicability. The statistical power of the assessment system proposed above is not known. It remains to be determined how well SC0-24 AUC can discriminate between ICS formulations that differ in systemic activity by as little as $\pm 20 \%$. This, and the sample sizes needed to accomplish this, need to be systematically defined by pilot studies in order to confirm the practicability of the proposed procedure.

A direct pharmacokinetic measurement of systemic availability offers an alternative to the pharmacodynamic approach outlined above. If greater precision could be achieved with the pharmacokinetic measure this could reduce sample size requirements and operating costs. However, the development of analytical methods for detecting various exogenous corticosteroids has been difficult historically, and changes in SC0-24 AUC values may occur in association with serum levels of the drug below the lower limit of quantification. Additionally, pharmacokinetic and pharmacodynamic parameters are equally vulnerable to extraneous factors such as variability in intrapulmonary delivery due to faulty inhalation technique with one or other of the comparator drugs. And, finally, an opinion as to the clinical relevance of such pharmacokinetic data is ultimately dependent on supporting pharmacodynamic evidence.

Simultaneous or separate assessment of safety and efficacy. To maximize the statistical power of the comparison and strengthen the regulatory decision, it is advisable to assess safety and efficacy separately, using healthy and asthmatic subjects, respectively. 
If the initial test in healthy subjects finds the TD and $\mathrm{SD}$ to be systemically equivalent, their relative efficacies must then be determined in patients. If the TD proves less active systemically than the SD according to the criteria outlined above under Regulatory interpretation, further testing for relative efficacy may be considered. If, on the other hand, the TD proves more active systemically than the SD, further testing for relative efficacy is not indicated (and is economically and ethically undesirable).

Ethical considerations. The choice of SC0-24 AUC rather than ACTH responsiveness as the favoured response index (see Response index section, above) circumvents the ethical and legal liability concerns associated with the anaphylactogenic potential of repeated ACTH injections. These preclude its use in some jurisdictions.

The brief duration of the systemic effect of single doses of the drugs, coupled with the domiciliary observation of each test subject throughout the period of active treatment, conform with current standards for the ethical conduct of health sciences research involving human subjects. Safety standards based on adult data may reasonably be applied to children as well, since children metabolize glucocorticoids more rapidly than adults $[162,163]$.

Summary. A process has been described for comparing the systemic activities of generic versus standard formulations of anti-asthmatic inhaled steroid, for regulatory purposes. A pharmacodynamic approach is favoured over a direct pharmacokinetic measurement of systemic availability.

Pilot studies would be needed to document: 1) the capacity of this procedure to discriminate between formulations that differ in systemic potency to a small but potentially clinically important degree; and 2) the reproducibility of such estimates of systemic bioequivalence within and between investigative centres.

Additionally, methodological studies are advisable to determine whether laboratory measures of bone turnover such as serum osteocalcin or the urinary output of crosslinked $\mathrm{N}$ telopeptides can be refined to achieve levels of precision comparable to those attainable with $\mathrm{SCO}-24$ AUC, and whether the former might be substituted for SC0-24 AUC to provide an equally efficient but more clinically valid estimate of the safety of different formulations of ICS.

Finally, the general principles of this approach to comparing generic versus standard formulations of ICS would appear equally applicable to comparisons between different ICS drugs, delivery devices and/or propellant systems.

\section{Appendix}

In contrast to the within-drug comparisons discussed above, comparisons between pharmacokinetically dissimilar ICS drugs need to be based on multiple dosing to steady state. The duration of treatment is conventionally Ś4 times the terminal plasma half-life of the most slowly metabolized of the drugs [164]. Three day treatment periods have been used for comparing fluticasone (half-life $=$ $14.4 \mathrm{~h}$ ) with other ICS in terms of their effects on $\mathrm{SC} 0-24$ AUCs [130, 142]. The variance of the SC0-24 AUC response to fluticasone at steady state may be considera- bly larger than with single dosing [130]. This and its implications with respect to sample size requirements need to be taken into consideration when comparing the systemic activity of fluticasone with other ICS.

\begin{abstract}
Acknowledgements: The authors would like to thank J. Bramley and B. Davis for assisting in the preparation of this manuscript and K.F. Read and P. Roufail for their help and support in organizing these meetings and producing this report. They are also indebted to R. Brus, C. Bayliff, M. Brannan, J. Corren, S. Edsbäcker, R. Fuller, L. Hendeles, J. Jenkins and S. Szefler for helpful information and advice.

Participants to the symposia: R. Ahrens (Iowa City, USA); L-P. Boulet (Sainte-Foy, Québec, Canada); K.Chapman (Toronto, Canada); D.W. Cockcroft (Saskatoon, Canada); P. Gibson (Newcastle, Australia); F.E. Hargreave (Hamilton, Canada); L. Hendeles (Gainesville,USA); R. Pauwels (Gent, Belgium); K.F. Read (Toronto, Canada); P. Roufail (Ottawa, Canada); R. Ruffin (Woodville, Australia); P. Sterk (Leiden, Netherlands); A. Tattersfield (Nottingham, UK); J. Toogood (London, Canada); N. Zamel (Toronto, Canada).
\end{abstract}

\section{References}

1. American Thoracic Society Board of Directors. Standards for the diagnosis of patients with COPD and asthma. Am Rev Respir Dis 1987; 136: 225-244.

2. International consensus report on the diagnosis and management of asthma. Clin Exper Allergy 1992, 22 (Suppl.): $1-72$.

3. Ernst P, FitzGerald JM, Spier S. Canadian Asthma Consensus Conference: Summary of Recommendations. Can Resp J 1996; 3: 89-100.

4. Geddes BDM. Inhaled corticosteroids: benefits and risks. Thorax 1992; 47: 404-407.

5. Barnes PJ, Pedersen S, Busse WW. Efficacy and safety of inhaled corticosteroids: new developments. Am J Respir Crit Care Med 1998; 157: S1-S53.

6. Barnes PJ. Inhaled glucocorticoids for asthma. N Engl J Med 1995; 332: 868-875.

7. Martin GP, Onyechi JO, Marriott C. Future prospects for pulmonary delivery of drugs. S.T.P. Pharma Sciences 1994; 4: 5-10.

8. Spino M. Bioequivalence of generic aerosol bronchodilators: what are the issues? Can Med Assoc J 1989; 141: 883-887.

9. Wong BJO, Hargreave FE. Bioequivalence of metereddose inhaled medications. J Allergy Clin Immunol 1993; 92: 373-379.

10. Derom E, Pauwels R. Bioequivalence of inhaled drugs. Eur Respir J 1995; 8: 1634-1636.

11. Balmes JR, Chaisson R, Dolovich MB, et al. Aerosol consensus statement. Chest 1991; 100: 1106-1109.

12. Newhouse MT, Dolovich MB. Control of asthma by aerosols. N Engl J Med 1986; 315: 870-874.

13. Rogers DF, Ganderton D. Determining equivalence of inhaled medications. Workshop report. Resp Med 1995; 89: 253-261.

14. US. Pharmacopoeia 23 rd Ed. (National Formulary 18th Ed.): In vivo Bioequivalence Guidelines US Pharmacopeial Convention Inc. Rockville, MD. 1995; 1929-1932.

15. Toogood JH, Jennings B, Baskerville JC. Aerosol corticosteroids. In: Weiss EB, Segal MS, Stein M, eds. Bronchial Asthma, Mechanisms and Therapeutics. 2nd ed. Boston, Little, Brown 1985; pp. 698-713. 
16. Fiese EF, Gorman, Dolinsky D, et al. Test method for evaluation of loss of prime in metered-dose aerosols. $J$ Pharm Sci 1988; 77: 90-93.

17. Newman SP, Millar AB, Lennard-Jones TR, Moren F, Clarke SW. Improvement of pressurized aerosol deposition with Nebuhaler spacer device. Thorax 1984; 39: 935-941.

18. O'Callaghan C, Lynch J, Cant M, Robertson C. Improvement in sodium cromoglycate delivery from a spacer device by use of an antistatic lining, immediate inhalation, and avoiding multiple actuations of drug. Thorax 1993; 48: 603-606.

19. O'Callaghan C, Cant M, Robertson C. Delivery of beclomethasone dipropionate from a spacer device: what dose is available for inhalation? Thorax 1994; 49: 961964.

20. Hindle M, Newton DAG, Chrystin H. Dry powder inhalers are bioequivalent to metered-dose inhalers. Chest 1995; 107: 629-633.

21. Newman SP, Pavia D, Clarke SW. How should a pressurized beta-adrenergic bronchodilator be inhaled? Eur $J$ Respir Dis 1981; 62: 3-21.

22. Tashkin DP. Multiple dose regimens: impact on compliance. Chest 1995; 107: S176-S182.

23. O'Connor SA, Burns CP, Harrison DR, Hare JF, Cochrane GM. An aerosol actuation counter for the assessment of patient compliance to inhaled therapy. Am Rev Respir Dis 1990; 114 (4): 223A.

24. Yeung M, O'Connor SA, Parry DT, Cochrane GM. Compliance with prescribed drug therapy in asthma. Respir Med 1994; 88: 31-35.

25. Côté J, Robichaud $\mathrm{P}$, Boutin $\mathrm{H}$, et al. Compliance to peak expiratory flow (PEF) measurements in long-term follow-up of asthma. J Allergy Clin Immunol 1996; 97: 258.

26. Schuirmann DJ. A comparison of the two one-sided test procedure and the power approach for assessing equivalence of average bioavailability. J Pharmacokinet Biopharm 1987; 15: 657-680.

27. Lipworth BJ. Clinical pharmacology of corticosteroids in bronchial asthma. Pharm Ther 1993; 58: 173-209.

28. Toogood JH, Lefcoe NM, Haines DSM, et al. A graded dose assessment of the efficacy of beclomethasone dipropionate aerosol for severe chronic asthma. J Allergy Clin Immunol 1977; 59: 248-308.

29. Toogood JH, Baskerville J, Jennings B, Lefcoe NM, Johansson SA. Bioequivalent doses of budesonide and prednisone in moderate and severe asthma. J Allergy Clin Immunol 1989; 84: 688-700.

30. Gagnon M, Côté J, Milot J, Turcotte H, Boulet LP. Comparative safety and efficacy of single or twice daily administration of inhaled beclomethasone in moderately severe asthma. Chest 1994; 105: 1732-1737.

31. Weiner P, Weiner M, Azgad Y. Long term clinical comparison of single versus twice daily administration of inhaled budesonide in moderate asthma. Thorax 1995; 50: 1270-1273.

32. Reinberg A, Halberg F, Falliers CJ. Circadian timing of methylprednisolone effects in asthmatic boys. Chronobiologia 1974; 1: 333-347.

33. Boulet LP, Robson R, Stepner N. Clinical equivalence of once $v s$ twice daily administration of inhaled fluticasone propionate in the treatment of mild and moderate asthma. Eur Respir J 1996; 9: Suppl. 23, 52s.

34. Lipworth BJ. New perspectives on inhaled drug delivery and systemic bioactivity. Thorax 1995; 50: 105-110.

35. Hatoum HT, Schumock GT, Kendzierski DL. Meta-anal- ysis of controlled trials of drug therapy in mild chronic asthma: the role of inhaled corticosteroids. Ann Pharmacother 1994; 28: 1285-1289.

36. Davies B. A comparison of beclomethasone dipropionate and budesonide in the treatment of asthma. $\mathrm{Br} J \mathrm{Clin}$ Pract 1993; 47: 87-93.

37. Stiksa G, Glennow C, Johannesson N. An open crossover trial with budesonide and beclomethasone dipropionate in patients with bronchial asthma. Eur J Respir Dis 1982; 63: 266-267.

38. Kjellman M, Moller C, Gennow C, Konar A. A comparison of "becotide" and budesonide in children. Eur $J$ Respir Dis 1982; 63: Suppl. 124, 127.

39. Baran D. A comparison of inhaled budesonide and beclomethasone dipropionate in childhood asthma. $\mathrm{Br} J \mathrm{Dis}$ Chest 1987; 81: 170-175.

40. Bjorkander J, Formgren H, Johansson SA, Millquist E. Methodological aspects on clinical trials with inhaled corticosteroids: results of two comparisons between two steroids aerosol in patients with asthma. Eur J Respir Dis 1982; 63: Suppl. 122, 108-117.

41. Field HV, Jenkinson PMA, Frame MH, Warner JO. Asthma treatment with a new corticosteroid aerosol budesonide administered twice daily by spacer inhaler. Arch Dis Child 1982; 57: 864-866.

42. Rafferty P, Tucker LG, Frame MH, Fergusson RJ, Biggs BA, Crompton GK. Comparison of budesonide and beclomethasone dipropionate in patients with severe chronic asthma: Assessment of relative prednisolone-sparing effects. Br J Dis Chest 1985; 79: 244-250.

43. Tjwa MKT. Budesonide inhaled via Turbuhaler: a more effective treatment for asthma than beclomethasone dipropionate via Rotahaler. Ann Allergy Asthma Immunol 1995; 75: 107-111.

44. Springer C, Avital A, Maayan CH, Rosier A, Godfrey S. Comparison of budesonide and beclomethasone dipropionate for treatment of asthma. Arch Dis Child 1987; 62: 815-819.

45. Boe J, Rosenhall L, Alton M, et al. Comparison of dose-response effects of inhaled beclomethasone dipropionate in the management of asthma. Allergy 1989; 44: 349-355.

46. Petrie GR, Choo-Kang YFJ, Clark RA, et al. An assessment of the acceptability of two breath-actuated corticosteroid inhalers: comparison of "Turbohaler" with "Diskhaler". Drug Invest 1990; 2: 129-131

47. Selroos O, Backman R, Forsen KO, et al. Clinical efficacy of budesonide Turbuhaler compared with that of beclomethasone dipropionate pMDI with volumatic spacer. A 2-year randomized study in 102 asthma patients. Allergy 1994; 49: 833-836.

48. Svendsen UG, Frolund L, Heinig JH, Madsen F. Highdose inhaled steroids in the management of asthma. A comparison of the effects of budesonide and beclomethasone dipropionate on pulmonary function, symptoms, bronchial responsiveness and the adrenal function. Allergy 1992; 47: 174-180.

49. Tjwa MKT. Budesonide Turbuhaler (BUD) vs Beclomethasone Rotahaler (BDP) on histamine PC20 and FEV1. Eur Respir J 1990; 3: Suppl. 10, 161s-162s.

50. Gustaffson P, Tsanakas J, Gold M. Comparison of the efficacy and safety of inhaled fluticasone propionate 200 micrograms/day with inhaled beclomethasone dipropionate $400 \mathrm{micrograms} /$ day in mild and moderate asthma. Arch Dis Child 1993; 69: 206-211.

51. Leblanc P, Mink S, Keistinen, Saarelainen PA, Ringdal N, Payne SL. A comparison of fluticasone dipropionate 200 
$\mu \mathrm{g} /$ day with beclomethasone dipropionate $400 \mu \mathrm{g} /$ day in adult asthma. Allergy 1994; 49: 380-385.

52. Dahl R, Lundback B, Malo JL, Mazza J, Nieminen MM, Soarelainen P, Barnacle H. A dose-ranging study of fluticasone propionate in adult patients with moderate asthma. Chest 1993; 104: 1352-1358.

53. Fuller R, Johnson M, Bye A. Fluticasone propionate - an update on preclinical and clinical experience. Respir Med 1995; 89 (Suppl. A): 3-18.

54. Bootsma GP, Dekhuijzen PNR, Festen J, Mulder PGH, Van Herwaarden CLA. Comparison of fluticasone propionate and beclomethasone dip ropionate on direct and indirect measurements of bronchial hyperresponsiveness in patient with stable asthma. Thorax 1995; 50: 10441050.

55. Ayres JG, Bateman ED, Lundback B, Harris TAJ . High dose fluticasone propionate, $1 \mathrm{mg}$ daily, versus fluticasone propionate, $2 \mathrm{mg}$ daily, or budesonide, $1.6 \mathrm{mg}$ daily, in patients with chronic severe asthma. Eur Respir $J$ 1995; 8: 579-586.

56. Lundback B, Alexander M, Day J, Hébert J, et al. Evaluation of fluticasone propionate $\left(500 \mu \mathrm{g} \cdot \mathrm{day}^{-1}\right)$ administered either as dry powder via a Diskhaler inhaler or pressurized inhaler and compared with beclomethasone dipropionate $\left(1000 \mu \mathrm{g} \cdot \mathrm{day}^{-1}\right)$ administered by pressurized inhaler. Respir Med 1993; 87: 609-620.

57. Fabbri L, Burge PS, Croonenborgh L, Warlies F, Ciaccia A, Parker C. Comparison of fluticasone propionate with beclomethasone dipropionate in moderate to severe asthma treated for one year. Thorax 1993; 48: 817-823.

58. Langdon CG, Capsey LJ and the UK study group. Fluticasone propionate and budesonide in adult asthmatics: a comparison using dry-powder inhaler devices. $\mathrm{Br} \mathrm{J} \mathrm{Clin}$ Res 1994; 5: 85-99.

59. Langdon CG, Thompson J. A multi-centre study to compare the efficacy and safety of inhaled fluticasone propopionate and budesonide via metered dose inhalers in adults with mild-to-moderate asthma. Br J Clin Res 1994; 5: 73-84.

60. Djukanovic R, Walls A,Wilson JW, et al. The effect of inhaled beclomethasone dipropionate (BDP) on airway mast cells, histamine and tryptase in atopic asthma. Am Rev Respir Dis 1991; 143: A627.

61. Laitinen LA, Laitinen A, Haabtela T. A comparative study of the effects of an inhaled corticosteroid, budesonide, and a $\beta_{2}$-agonist, terbutaline, on airway inflammation in newly diagnosed asthma: a randomized, double-blind, parallel-group controlled trial. J Allergy Clin Immunol 1992; 90: 32-42.

62. Hargreave FE, Pizzichini E, Pizzichini MMM. Assessment of airway inflammation. In: Barnes P, Grunstein M, Leff A, Woolcock A, eds. Asthma. Philadelphia, Lippincott-Raven 1997. Vol. 2, pp. 1433-1450.

63. Pizzichini E, Pizzichini MMM, Efthimiadis A, et al. Indices of airway inflammation in induced sputum: reproducibility and validity of cell and fluid phase measurements. Am J Respir Crit Care Med 1996; 154: 308-317.

64. Pizzichini MMM, Pizzichini E, Clelland L, et al. Sputum in severe exacerbations of asthma: kinetics of inflammatory indices after prednisone treatment. Am J Respir Crit Care Med 1997; 155: 1501-1508.

65. Cockcroft DW, Swystun VA. Asthma control versus asthma severity. J Allergy Clin Immunol 1996; 98: 10161018.

66. Makuch RW, Johnson MF. Some issues in the design and interpretation of "negative" clinical studies. Arch Intern Med 1986; 146: 986-989.
67. Detsky AS, Sackett DL. When was a "negative" clinical trial big enough? How many patients you needed depends on what you found. Arch Intern Med 1985; 145: 709-712.

68. Goodman SN, Berlin JA. The use of predicted confidence intervals when planning experiments and the misuse of power when interpreting results. Ann Intern Med 1994; 121: 200-206.

69. Gardner MJ, Altman DG. Confidence intervals rather than $\mathrm{p}$ values: estimation rather than hypothesis testing. Br Med J 1986; 292: 746-750.

70. Detsky AS, Sackett DL. Establishing therapeutic equivalency. What is a clinically significant difference? Arch Intern Med 1986; 146: 861-862.

71. Louis TA, Lavori PW, Bailar JC, Polansky M. Crossover and self-controlled designs in clinical research. $N$ Engl $J$ Med 1984; 310: 24-31.

72. Juniper EF, Kline PA, Vanzieleghem MA, Hargreave FE. Reduction of budesonide after a year of increased use: a randomized controlled trial to evaluate whether improvements in airway responsiveness and clinical asthma are maintained. J Allergy Clin Immunol 1991; 87: 483-489.

73. Kamada AK, Szefler S. Mechanisms of action of glucocorticoids in asthma and rhinitis. In: Busse WW, Holgate ST, eds. Asthma and rhinitis. Boston, Blackwell Scientific Publications 1995; pp. 1255-1266.

74. Bailey WC, Wilson SR, Weiss KB, et al. Measures for use in asthma clinical research: overview of the NIH workshop. Am J Respir Crit Care Med 1994; 149: S1-S8.

75. Spitzer WO, Suissa S, Ernst P, et al. The use of $\beta$-agonists and the risk of death and near from asthma. $N$ Engl J Med 1992; 326: 501-506.

76. Juniper EF, Guyatt GH, Willan A, Griffith LE. Determining a minimal important change in a disease-specific quality of life questionnaire. J Clin Epidemiol 1994; 47: 81-87.

77. Juniper EF, Guyatt GH, Ferrie PJ, Griffith LE. Measuring quality of life in asthma. Am Rev Respir Dis 1993; 147: 832-838

78. American Thoracic Society. Standards for the diagnosis and care of patients with chronic obstructive pulmonary disease. Am J Respir Crit Care Med 1995; 152: S77-S120.

79. Carey VJ, Weiss ST, Tager IB, Leeder SR, Speizer FE. Airways responsiveness, wheeze onset, and recurrent asthma episodes in young adolescents. Am J Respir Crit Care Med 1996; 153: 356-361.

80. Nguyen BP, Wilson S, German DF. Patient's perceptions compared with objective ratings of asthma severity. Ann Allergy Asthma Immunol 1996; 77: 209-215.

81. Juniper EF, Kline PA, Vanzieleghem MA, et al. Effect of long-term treatment with an inhaled corticosteroid (Budesonide) on airway hyperresponsiveness and clinical asthma in nonsteroid-dependent asthmatics. Am Rev Respir Dis 1990; 142: 832-836.

82. Kraan J, Koëter GH, Mark TWVD, et al. Changes in bronchial hyperreactivity induced by 4 weeks of treatment with antiasthmatic drugs in patients with allergic asthma: a comparison between budesonide and terbutaline. J Allergy Clin Immunol 1985; 76: 628-636.

83. Kraan J, Koëter GH, Mark TWVD, et al. Dosage and time effects of inhaled budesonide on bronchial hyperreactivity. Am Rev Respir Dis 1988; 137: 44-48.

84. Waalkens HJ, Gerritsen J, Koëter GH, et al. Budesonide and terbutaline or terbutaline alone in children with mild asthma: effects o $\mathrm{n}$ bronchial hyperresponsiveness and diurnal variation in peak flow. Thorax 1991; 46: 499-503.

85. Bel EH, Timmers MC, Hermans J, et al. The long-term effects of nedocromil sodium and beclomethasone dipropionate on bronchial responsiveness to methacholine in 
nonatopic asthmatic subjects. Am Rev Respir Dis 1990; 141: 21-28.

86. Avital A, Springer C, Bar-Yishay E, Godfrey S. Adenosine, methacholine, and exercise challenges in children with asthma or paediatric chronic obstructive pulmonary disease. Thorax 1995; 50: 511-516.

87. Cockcroft DW, Hargreave FE. Airway hyperresponsiveness: definition, measurement, and clinical relevance. In: Kaliner MA, Barnes PJ, Persson CGA, eds. Asthma: Its Pathology and Treatment. New York, Marcel DeLker, Inc. 1991; pp. 51-72.

88. Pauwels R, Joos G, Van Der Straeten M. Bronchial hyperresponsiveness is not bronchial hyperresponsiveness is not bronchial asthma. Clin Allergy 1988; 18: 317321.

89. Cockcroft DW, Killian DN, Mellon JJA, Hargreave FE. Protective effect of drugs on histamine-induced asthma. Thorax 1977; 32: 429-437.

90. Kerribijn KF, van Essen-Zandvliet EEM, Neijens HJ. Effects of long-term treatment with inhaled corticosteroids and beta-agonists on the branchial responsiveness in children with asthma. J Allergy Clin Immunol 1987; 79: 653-659.

91. Du Toit JI, Salome CM, Woolcock AJ. Inhaled corticosteroids reduce the severity of bronchial hyperresponsiveness in asthma but oral thophylline does not. Am Rev Respir Dis 1987; 136: 1174-1178.

92. Woolcock AJ, Yan K, Salome CM. Effect of therapy on bronchial hyperresponsiveness in the long-term management of asthma. Clin Allergy 1988; 18: 165-176.

93. Jenkins CR, Woolcock AJ. Effect of prednisone and beclomethasone dipropionate on airway responsiveness in asthma: a comparative study. Thorax 1988; 43: 378-384.

94. Juniper EF, Kline PA, Vanzieleghem MA, Ramsdale EH, O'Byrne PM, Hargreave FE. Long-term effects of budesonide on airway responsiveness and clinical asthma severity in inhaled steroid-dependent asthmatic subjects. Eur Respir J 1990; 3: 1122-1127.

95. Van Essen-Zandvliet EE, Hughes MD, Waalkens HJ, Duiverman EJ, Pocock SJ, Kerrebijn KF, The Dutch Chronic Non-specific Lung Disease Study Group. Effects of 22 months of treatment with inhaled corticosteroids and/or beta-2 agonists on lung function, airway responsiveness, and symptoms in children with asthma. Am Rev Respir Dis 1992; 146: 547-554.

96. Bel EH, Timmers MC, Zwinderman AH, Dijkman JH, Sterk PJ. The effect of inhaled corticosteroids on the maximal degree of airway narrowing to methacholine in asthmatic subjects. Am Rev Respir Dis 1991; 143: 109113.

97. Kerstjens HAM, Brand PLP, Hughes MD, et al., The Dutch Chronic Non-specific Lung Disease Study Group. A comparison of bronchodilator therapy with or without inhaled corticosteroid therapy for obstructive airways disease. N Engl J Med 1992; 327: 1413-1419.

98. Wempe JB, Postma DS, Breederveld N, Alting-Hebing D, van der Mark TW, Koeter GH. Separate and combined effects of corticosteroids and bronchodilators on airflow obstruction and airway hyperresponsiveness in asthma. $J$ Allergy Clin Immunol 1992; 89: 679-687.

99. Cockcroft DW, Swystun VA, Bhagat R. Interaction of inhaled $\beta_{2}$ agonist and inhaled corticosteroid on airway responsiveness to allergen and methacholine. Am J Respir Crit Care Med 1995; 152: 1485-1489.

100. Barnes PJ. Effect of corticosteroids on airway hyperresponsiveness. Am Rev Respir Dis 1990; 141: S70-S76.

101. Henriksen JM. Effect of inhalation of corticosteroids on exercise induced asthma: randomised double blind crossover study of budesonide in asthmatic children. Br Med J 1985; 291: 248-249.

102. Molema J, van Herwaarden CLA, Folgering HT. Effects of long-term treatment with inhaled cromoglycate and budesonide on bronchial hyperresponsiveness in patients with allergic asthma. Eur Respir J 1989; 2: 308316.

103. O'Connor BJ, Ridge SM, Barnes PJ, Fuller RW. Greater effect of inhaled budesonide on adenosine 5'-monophosphate-induced than on sodium metabisulfite-induced bronchoconstriction in asthma. Am Rev Respir Dis 1992; 146: 560-564.

104. Rodwell LT, Anderson SD, Seale JP. Inhaled corticosteroids modify bronchial responses to hyperosmolar saline. Eur Respir J 1992; 5: 953-962.

105. Fuller RW, Choudry NB, Eriksson G. Action of budesonide on asthmatic bronchial hyperresponsiveness: effects on directly and indirectly acting bronchodilators. Chest 1991; 100: 670-674.

106. Vathenen AS, Knox AJ, Wisniewski A, Tattersfield AK. Effect of inhaled budesonide on bronchial reactivity to histamine, exercise, and eucapnic dry air hyperventilation in patients with asthma. Thorax 1991; 46: 811-816.

107. Henriksen JM, Dahl R. Effects of inhaled budesonide alone and in combination with low-dose terbutaline in children with exercise-induced asthma. Am Rev Respir Dis 1983; 128: 993-997.

108. Groot CAR, Lammers J-WJ, Molema J, Festen J, van Herwaarden CLA. Effect of inhaled beclomethasone and nedocromil sodium on bronchial hyperresponsiveness to histamine and distilled water. Eur Respir J 1992; 5: 1075-1082.

109. Cockcroft DW. Bronchial inhalation tests II: measurement of allergic (and occupational) bronchial responsiveness. Ann Allergy 1987; 59: 89-99.

110. Booij-Noord H, Orie NGM, Devries K. Immediate and late bronchial obstructive ractions to inhalation of house dust and protective effects of disodium cromoglycate and prednisolone. J Allergy Clin Immunol 1971; 48: 344354.

111. Cockcroft DW, Murdock KY. Comparative effects of inhaled salbutamol, sodium cromoglycate and beclomethasone dipropionate on allergen-induced early asthmatic responses, late asthmatic responses and increased bronchial responsiveness to histamine. J Allergy Clin Immunol 1987; 79: 734-740.

112. Dahl R, Johansson S-A. Importance of duration of treatment with inhaled budesonide on the immediate and late bronchial reaction. Eur J Respir Dis 1982; 62 (Suppl 122): 167-175.

113. Wong BJ, Dolovich J, Ramsdale EH, et al. Formoterol compared with beclomethasone and placebo on allergen-induced asthmatic responses. Am Rev Respir Dis 1992; 146: 1158-1160.

114. Van Der Star JG, Berg WC, Steenhuis EJ, Devries K. Invloed van beclometasondipropionaat per aerosol op de obstructieve reactie in de bronchien na huisstofinhalatie. Ned T Geneesk 1976; 120: 1928-1932.

115. Burge PS, Efthimiou J, Turner-Warwick M, Nelmes PTJ. Double-blind trials of inhaled beclomethasone dipropionate and fluocortin butyl ester in allergen-induced immdiate and late ractions. Clin Allergy 1982; 12: 523-531.

116. De Baets FM, Goeteyn M, Kerrebijn KF. The effect of two months of treatment with inhaled budesonide on bronchial responsiveness to histamine and house-dust mite antigen in asthmatic children. Am Rev Respir Dis 
1990; 142: 581-586.

117. Pizzichini MMM, Kidney JC, Wong BJO, et al. Effect of salmeterol compared with beclomethasone on allergeninduced asthmatic and inflammatory responses. Eur Respir J 1996; 9: 449-455.

118. Cockcroft DW, McParland CP, O'Byrne PM, et al. Beclomethasone given after the early asthmatic response inhibits the late response and the increased methacholine responsiveness and cromolyn does not. J Allergy Clin Immunol 1993; 91: 1163-1168.

119. Swystun VA, Bhagat R, Kalra S, Jennings B, Cockcroft DW. Comparison of three diffrent doses of budesonide and placebo on the allergen-induced early asthmatic response (EAR). J Allergy Clin Immunol 1996; 97: 251.

120. McCubbin MM, Milavetz G, Grandgeorge S, et al. A bioassay for topical and systemic effect of three inhaled corticosteroids. Clin Pharmacol Ther 1995; 57: 455-460.

121. Kidney JC, Cockcroft DW, Hargreave FE, Boulet LP, Jennings B. Evaluation of inhaled corticosteroid activity using single doses and allergen challenge model. $\mathrm{J}$ Allergy Clin Immunol 1997; 100: 65-70.

122. Marshik PL, Thomas D, Ahrens R, Braver H, Hendeles L. Dose-response of inhaled beclomethasone (B) for attenuating the airway responses to allergen. $J$ Allergy Clin Im-munol 1996; 97: 316.

123. Agertoft L, Pedersen S. A randomized double-blind dose reduction study to compare the minimal effective dose of budesonide turbuhaler and fluticasone propionate diskhaler. J Allergy Clin Immunol 1997; 99: 773-780.

124. Turner MO, Hussack P, Sears MR, Dolovich J, Hargreave FE. Exacerbations of asthma without sputum eosinophilia. Thorax 1995; 50: 1057-1061.

125. Parameswaran K, Pizzichini MMM, Pizzichini E, Jeffery PK, Hargreave FE. Mistaken prednisone-dependent asthma: serial sputum cell counts in disease management. Eur Respir J 1998; in press

126. Gibson PG, Wong BJO, Hepperle MJE, et al. A research method to induce and examine a mild exacerbation of asthma by withdrawal of inhaled corticosteroid. Clin Exp Allergy 1992; 22: 525-532.

127. Hubert JJ. Bioassay. 3rd ed. Dubuque, Iowa, Kendall/ Hunt Publishing Co. 1992.

128. Lipworth BJ. Airways and systemic effects of inhaled corticosteroids in asthma: dose response relationship. Pulm Pharmacol 1996; 9: 19-27.

129. Hogger P, Rohdewald P. Binding kinetics of fluticasone propionate to the human glucocorticoid receptor. Steroids 1994; 59: 597-602.

130. Corren J, Rachelefsky G, Hochhaus G. A five-way parallel randomized study to compare the safety profile of beclomethasone dipropionate (BDP), budesonide (BUD), flunisolide (FLU), fluticasone propionate (FP), and triamcinolone acetonide (TA) in healthy male volunteers. Chest 1996; 110: 83s.

131. Jones B, Jarvis P, Lewis JA, Ebbutt AF. Trials to assess equivalence: the importance of rigorous methods. Br Med J 1996; 313: 36-39.

132. Kirshner B. Methodological standards for assessing therapeutic equivalence. J Clin Epidemiol 1991; 44: 839849.

133. Hauck WW, Anderson S. A proposal for interpreting and reporting negative studies. Stat Med 1986; 5: 203-209.

134. Toogood JH, Crilly RG, Jones G, Nadeau J, Wells GA. Effect of high dose inhaled budesonide on calcium and phosphate metabolism and the risk of osteoporosis. Am Rev Respir Dis 1988; 138: 57-61.

135. Hodsman AB, Toogood JH, Jennings B, Fraher LJ, Bask- erville JC. Differential effects of inhaled budesonide and oral prednisone on serum osteocalcin. J Clin Endocrin Metab 1991; 72: 530-540.

136. Toogood JH. Complications of topical steroid therapy for asthma. Am Rev Respir Dis 1990; 141: s89-s96.

137. Adachi JD, Baensen WG, Hodsman AB. Corticosteroid-induced osteoporosis. Semin Arthritis Rheum 1993; 22: $375-384$.

138. Feiss G, Morris R, Rom D, et al. A comparative study of the effects of intranasal triamcinolone acetonide aerosol (ITAA) and prednisone on adrenocortical function. $J$ Allergy Clin Immunol 1992; 89: 1151-1156.

139. Edabäcker S, Larsson P, Nilsson M, Wirén JE. Astra Draco AB, Lund, Sweden. Budesonide controlled release (CIR) capsules affect plasma cortisol less than prednisone tablets. Poster at World Congress of Gastroenterology, 1994.

140. Grahnén A, Eckernäs S-A, Brundin RM, Ling-Andersson A. An assessment of the systemic activity of single doses of inhaled fluticasone propionate in healthy volunteers. Br J Clin Pharmacol 1994; 38: 521-525.

141. Grahnén A, Brundin AM, Ling-Andersson A, Lonnebo, A. Eckernäs SA, PMC Contract Research AB, Uppsala, Sweden. The systemic potency of fluticasone propionate from Diskhaler ${ }^{\circledR} v$ budesonide from Turbuhaler®. Am J Respir Crit Care Med 1996; 153 (part 2): A338.

142. Boorsma M, Andersson N, Larsson P, Ullman A. Assessment of the relative systemic potency of inhaled fluticasone and budesonide. Eur Respir J 1996; 9: 1427-1432.

143. Aaronson D, Kaiser H, Dockhorn R, Findlay S, Korenblat P, Thorsson L, Kallen A. Effects of budesonide via Turbuhaler ${ }^{\circledR}$ on the HPA-axis in asthmatics: a dose res-ponse study. J Allergy Clin Immunol 1998; 101: 312-319.

144. Zanen P, Lammers J-WJ. Sample sizes for comparative inhaled corticosteroid trials with emphasis on showing therapeutic equivalence. Eur J Clin Pharmacol 1995; 48: 179-184.

145. SAS Institute Inc. SAS/STAT User's Guide. 4th ed. Cary, N.C. SAS Institute Inc. 1989; p. 846.

146. Maunsell K, Pearson RSB, Livingstone JL. Long-term corticosteroid treatment of asthma. Br Med J 1968; 1: 661-665.

147. Lieberman P, Patterson R, Kunske R. Complications of long-term steroid therapy for asthma. J Allergy Clin Immunol 1972; 49: 329-336.

148. Kehlet H, Binder C. Adrenocortical function and clinical course during and after surgery in unsupplemented glucocorticoid treated patients. Br J Anaesth 1973; 45: 10431048.

149. Plumpeon FS, Besser GM. The adrenocortical response to surgery and insulin-induced hypoglycaemia in corticosheroid-treated and normal subjects. Br J Surg 1969; 56(3): 216-219.

150. Plumpton FS, Besser GM, Cole PV. Corticosteroid treatment and surgery. Anaesthesia 1969; 24: 3-11.

151. Kehlet H, Binder C. Value of an ACTH test in assessing hypothalamic-pituitary-adrenocortical function in glucocorticoid treated patients. Br Med J 1973; 2: 147-149.

152. Mellis CM, Phelan PD. Asthma deaths in children - a continuing problem. Thorax 1977; 32: 29-34.

153. Adinoff AD, Hollister JR. Steroid-induced fracture and bone loss in patients with asthma. N Engl J Med 1983; 309: 205-268.

154. Ruegsegger P, Medici TC, Anliker M. Corticosteroid-induced bone loss. A longitudinal study of alternate day therapy in patients with bronchial asthma using quantitative computed tomography. Eur J Clin Pharmacol 1983; 25: 615-620. 
155. Hodsman A, Haddad R, Markov A, Baskerville J, Toogood $\mathrm{JH}$. Associations of long term inhaled (I-S) or oral steroid (O-S) therapy with vertebral fracture in asthmatic adults. J Clin Invest Med 1993; 6: B6 (Abstract).

156. Lukert BP, Raisz LG. Glucocorticoid-induced osteoporosis: pathogenesis and management. Ann Intern Med 1990; 112: 352-364.

157. Kanis JA. What constitutes evidence for drug efficacy in osteoporosis? Drugs and Aging 1993; 3: 391-399.

158. Toogood JH, Baskerville J, Markov AE, et al. Bone mineral density and the risk of fracture in patients receiving long-term inhaled steroid therapy for asthma. J Allergy Clin Immunol 1995; 96: 157-166.

159. Baskerville J, Toogood JH, Hodsman AB. Comparing the safety of generic (Gee) versus standard (STD) antiasthmatic inhaled steroids (I-S). Clin Invest Med 1997; 20: 53.

160. Toogood JH, Fraher LJ, Cheng S, Baskerville J. Serum osteocalcin (SO) and procollagen (PICP) as markers for osteoporotic fracture risk in steroid dependent asthmatics. J Allergy Clin Immunol 1996; 97: 354.

161. Dempster DW, Shen V, Brus RHP. Effects of fluticasone propionate on plasma cortisol and osteocalcin levels. Ann Allergy Asthma Immunol 1996. Abstract.

162. Ryrfeldt A, Andresson P, Edebacker S, Tonnesson M, Davies D, Pauwels R. Pharmacokinetics and metabolism of budesonide, a selective glucocorticoid. Eur J Respir Dis 1982; 63s: 86-95.

163. Pedersen S, Steffensen G, Ekman I, Tonnesson M, Borga O. Pharmacokinetics of budesonide in children with asthma. Eur J Clin Pharmacol 1987; 31: 579-582.

164. Winter ME, Katcher BS, Koda-Kimble MA. Basic Clinical Pharmacokinetics. Applied Therapeutics Inc. Spokane, WA, 1980. 